\title{
El Reto vertical ANDino. Desafíos de la gravedad en LAS SOCIEDADES ANDINAS PRECOLONIALES
}

\begin{abstract}
Aldo Bolaños*
\section{Resumen}

El autor propone en el presente ensayo una mirada diferente del espacio andino, una perspectiva integrada con la geografía y sus entornos paisajísticos. Respaldado por los datos arqueológicos e históricos en temas como la arquitectura, la agricultura y el mismo paisaje cultural, plantea un entendimiento integrado y alternativo de las sociedades andinas precoloniales enfocado en alternativas de desarrollo, para finalmente llamar la atención de los riesgos y amenazas que actualmente presenta el patrimonio cultural de la región.
\end{abstract}

Palabras clave

Verticalidad, paisaje cultural, mundo andino, patrimonio cultural.

\begin{abstract}
The author proposes in the present paper a different look from the Andean space, a integrated perspective with the geography and his landscape environments. Endorsed by the archaeological and historical information in topics as the architecture, the agriculture and the same cultural landscape, the author raises an integrated and alternative understanding of the andean societies precoloniales focused in alternatives of development, finally calling the attention of the risks and threats that nowadays presents the cultural heritage of the region.
\end{abstract}

\section{Keywords}

Uprightness, cultural landscape, andean world, cultural heritage.

* Arqueólogo. Miembro fundador de la Asociación Arqueología para el Desarrollo, del Equipo Peruano de Antropología Forense - EPAF y de la Asociación Latinoamericana de Antropología Forense - ALAF. Actualmente lleva adelante la Iniciativa Paisaje y Memoria y también es investigador asociado a la Asociación Ukhupacha. Correo electrónico: 
El reto vertical andino es una de las características más espectaculares, singulares y excepcionales del Perú precolonial y del Perú actual.

Enfrentar el reto de la verticalidad extrema impuesto por la topografía andina, dio por resultado una alta civilización que usó exitosamente esta condición para la construcción de un paisaje articulado y altamente productivo, pero que, además, a partir de la obra humana, propiciaba la percepción espectacular de la belleza propia de los Andes integrando en una única visión, el cielo a la tierra y ésta a sus profundidades.

Dominar los retos de la verticalidad, implicaba no sólo superar el estrés biológico y psicológico que la altura sobre el nivel del mar genera al ser humano, sino asumir el desafío de la gravedad, reto implícito al de la verticalidad. Se afrontó el reto en base a una sabiduría basada en la milenaria acumulación de experiencias y de conocimiento de los elementos naturales (agua, fuego, tierra y madera, metal), de las energías como el viento, el calor o el frío y la fuerza humana ante la ausencia de máquinas; del conocimiento de las fuerzas de la naturaleza como la misma gravedad, fundamental para un medio vertical. Pero es en la maestría de su aprovechamiento mediante el manejo de la geografía, la geología, la ingeniería, la arquitectura, la agronomía o la hidrología y de las técnicas implícitas que permitieron la proyección vertical suficientemente segura sin perder la vida, es allí donde se encuentra su carácter singular y excepcional.

Desde los primeros pobladores arcaicos, entre 15 y 10 mil años atrás, habitantes de las cuevas, abrigos rocosos o campamentos en el desierto, hasta los constructores de pueblos y ciudades sobre los peñascos y cumbres de períodos posteriores, se vieron en la necesidad de articular el territorio mediante caminos al pie de los barrancos y precipicios mirando a los picos nevados, las quebradas o al mar; luego, con el desarrollo de la agricultura se requeriría la modelación de las erguidas laderas de las montañas mediante sistemas de andenes, terrazas y bancales agrícolas y otras formas de manejo del agua y el suelo que permitieran la construcción de espacios productivos; estas obras, sólo por mencionar algunas, todas producto de la inmensa necesidad de generar espacios horizontales por pequeños que fueran, debían permitir el desarrollo de la vida humana, altamente organizada y masiva como para domesticar los Andes.

Las obras que vencían la verticalidad representaban el futuro mismo. Por ello, los espacios verticales eran también articulados a las creencias y los ritos, de modo tal que hoy sea común encontrar las huellas del arte rupestre, muchas veces de tipo propiciatorio, o de tumbas en sitios inaccesibles, que no pudieron ser construidos sin el uso de procedimientos especiales y siempre riesgosos. Vencer a la verticalidad andina, era pues vencer a la muerte.

Al recorrer los Andes y especialmente el Perú, tanto en la sierra, en la costa o en el bosque tropical andino, las manifestaciones del reto vertical están aun presentes como "colgando", término muy usado por viajeros e investigadores, olvidadas en las cordilleras, esperando su conocimiento y su rescate para ser dadas a conocer al mundo como un ejemplo de las formas en que el hombre andino precolonial supo mantenerse en equilibrio entre las formas extremas de la naturaleza y sus formas de desarrollo social.

\section{LA VERTICALIDAD GEOGRÁFICA}

Los Andes imponen su verticalidad. Esta verticalidad, que no es solamente aquella que vemos desde la costa hacia el cielo, se inicia en realidad a $200 \mathrm{~km}$ al oeste, en el océano, a una profundidad marina de casi 7 mil metros desde el zócalo continental y se proyecta en sus partes más altas, hasta casi los 7 mil metros de altura sobre el nivel del mar ${ }^{1}$. La costa es en realidad sólo una pequeña cornisa de las laderas occi-

1 El mar andino, aquella parte del Océano Pacífico ubicado frente a los Andes Peruanos y chilenos, también es parte de la verticalidad. Los desplazamientos verticales o ascensión de masas de agua que cumplen la función de nutrir a las aguas superficiales que sostienen la riqueza hidrobiológica que alberga, así como la subida y bajada de las mareas por la influencia lunar, también influenciaron decididamente el desarrollo de las sociedades precoloniales. 
dentales de la cordillera de los Andes. La vida humana se da entre el nivel del mar y hasta los $4500 \mathrm{~m}$ de altura adonde aproximadamente empiezan los nevados². De la costa a las zonas más altas, se ha determinado la existencia de 7 pisos ecológicos distintos los cuales condicionaban las labores productivas, principalmente agrarias, tal como se da en la actualidad. ${ }^{3}$

En las partes más altas de la sierra se configura la organización vertical del territorio. De la sierra alta o de las montañas que bajan abruptamente desde ella, dependen en la costa y en la selva la vida humana y gran parte de su fauna y de su flora. Ambas originan su sistema hidrológico en las lagunas y ríos serranos que bajan hacia la selva al Este o hacia el Océano Pacífico al Oeste. En términos topográficos e hidrográficos, la gran organización vertical del Perú andino se da a partir de las cuencas que bajan hacia el Pacífico (cuenca del Pacífico) o de aquellas que bajan hacia la Amazonía (cuenca Amazónica). Ambas cuencas originaban sus principales ríos a alturas sobre los $4500 \mathrm{~m}$ haciendo que la vinculación de estas grandes conformaciones geográficas se dé justamente en la sierra. Esta necesaria interdependencia obligó a las sociedades precoloniales, las de "más arriba" y las de "más abajo", a articular un proyecto de territorio común no exento de conflictos pero también pleno de grandes logros.

Por otro lado, los Andes peruanos se encuentran en una zona de transición entre el área ecuatorial, las áreas tropicales y las zonas subtropicales. Los Andes en el Perú avanzan de norte

2 Con el cambio climático actual, las cumbres nevadas son cada vez más escasas y están cada día a más altura sobre el nivel del mar (Chacón, Jacay, Moreno 2005). Encima de los $4500 \mathrm{~m}$ se dan principalmente ocupaciones modernas de explotaciones mineras.

3 Los pisos ecológicos fueron determinados por Pulgar Vidal en 1941 (Pulgar Vidal 1967) y son los siguientes: chala $(0-500 \mathrm{msnm})$, yunga $(500-2500 \mathrm{msnm})$, quechua $(2500-3500 \mathrm{msnm})$, suni $(3500-4000 \mathrm{msnm})$, puna o jalca $(4100-4500 \mathrm{msnm})$, janca $(4800-6768)$ y el piso omagua en la cordillera oriental entre los 400 y los $800 \mathrm{msnm}$ ). Es necesario mencionar que existen otras divisiones ecoregionales para el Perú como las de Brack Egg (1986) pero que combinan regiones verticales y horizontales que no son el objetivo de este artículo. al Sur, desde una naturaleza verde, húmeda y fértil hacia una de carácter árido y seco; al norte, una cordillera de alturas generales más bajas (3000 msnm) y en la Sierra Central y Sur hasta cadenas montañosas nevadas muy altas (4500 $\mathrm{msnm}$ ). La Sierra Norte -debido a sus menores niveles altitudinales-, permitió el paso de la flora y fauna amazónica que caracteriza a esta región, mientras que en la zona central y sur se da una fauna y flora endémica, de carácter principalmente andina, en la que aquellas especies de procedencia amazónica fueron transportadas por el hombre remontando los pisos omagua, janca, jalca, y puna.

\section{Mal de Altura, verticalidad y COCA}

La adaptación a la altura, es decir, vencer el mal de altura, no es un factor genético sino un estado de acomodación del cuerpo a esta circunstancia ${ }^{4}$. La situación vertical afecta en la medida en que a más altura el mal se hace más agudo y plantea dos tipos de retos al cuerpo humano. El primero, la adaptación a la altura de los que viven permanentemente en un medio elevado y que a pesar de ello llevaron adelante grandes empresas constructivas principalmente a partir del empleo de la fuerza humana; el segundo, el moverse permanentemente entre ambientes geográficos de distintas alturas como parte de las actividades socioproductivas necesarias para articular el territorio andino. Empezaremos por una breve definición del mal de altura.

El mal de altura es la respuesta del cuerpo y la mente humana para adaptarse a la vida en las condiciones difíciles que la altura impone. Este estrés puede clasificarse en dos tipos: un estrés biológico y un estrés psicológico. Entre sus síntomas se mencionan los dolores de cabeza, fatiga (respiración corta y palpitaciones, desordenes del sueño), cianosis (color azulado de la

4 "León-Velarde (Fabiola) investiga sobre el funcionamiento de los sistemas del organismo ante la disminución del oxígeno y la flexibilidad fenotípica de los andinos para aclimatarse a esa situación, sin tener diferencia genética con los costeños". (Citado en: "A propósito de la FIFA y las ciudades andinas". Diario El Comercio 6 de junio 2007. Por Modesto Montoya, físico nuclear). 
piel o de las membranas mucosas, causada por una baja concentración de oxígeno en sangre), la eritremia (enfermedad debida a la elevación de la cantidad de glóbulos rojos en la sangre), parestesia (sensación o conjunto de sensaciones anormales, especialmente el hormigueo, adormecimiento o ardor que experimentan en la piel ciertos enfermos), tinnitus o acufeno (percepción de golpeos o pitidos en el oído que no proceden de ninguna fuente externa) (León Velarde 2007). Estos síntomas se dan por una hipoxia severa, es decir, al estar sometido a un déficit de oxígeno propio del aire que se respira en la altura a partir de los $2000 \mathrm{~m}$, produce una elevación de la presión pulmonar y la ventilación pulmonar con una cantidad elevada de dióxidos de carbono $\left(\mathrm{PCO}_{2}\right)$, la vasoconstricción de los tejidos circulatorios pulmonares y la vasodilatación venosa. Entre los síntomas subjetivos asociados al mal de altura se encuentra la depresión. Como hipótesis, se ha sugerido (Arregui et al. 1995) que la coca puede actuar como bloqueador efectivo del receptor de las catecolaminas, sustancia asociada a los síntomas de la hipoxia, de allí su uso por poblaciones de la Sierra de forma tradicional para combatir el mal de altura. ${ }^{5}$

La coca está asociada en su uso tradicional como un estimulante biológico para superar las condiciones de fatiga que la falta de oxígeno produce y para soportar las bajas temperaturas. Junto a estos papeles, la coca cumple también un papel psicosocial como integrador tanto al interior de las comunidades como en la organización del trabajo intercomunal. Como sabemos, estas dos formas de organización del trabajo fueron fundamentales durante la época precolonial para posibilitar la construcción de las grandes obras de transformación del paisaje natural en paisaje constructivo así como en toda aquella infraestructura que permitió la urbani-

5 "Es interesante que ancestralmente se hayan combatido los síntomas del mal de altura con hoja de coca. Ésta actúa bloqueando y disminuyendo el transportador de catecolaminas, precisamente el receptor que se ha encontrado incrementado en la hipoxia crónica experimental. No es extraño, que drogas que actúan como bloqueadores del transporte de catecolaminas (e.g. antidepresivos tricíclicos) sean útiles en el tratamiento preventivo de la migraña y de la depresión." (Arregui et al 1995) zación del territorio andino. Estas tareas implicaban el traslado de poblaciones desde las zonas más bajas hacia las zonas más altas y viceversa y junto a ellos el traslado de materias primas, recursos e instrumentos que hicieran posible tales construcciones.

Cuando un poblador de la costa, sometido a una oxigenación distinta de su cuerpo sube a las partes altas de los Andes, siente el conjunto de efectos citados con más intensidad que los que viven siempre allí. De todos modos, nadie está exento de las afectaciones que la hipoxia provoca al cuerpo humano y de las reacciones defensivas de este.

Por último, como factor psicológico de la verticalidad cabe mencionar que la exposición permanente a caminar por los bordes de los precipicios y las laderas andinas genera percepciones del vacío que impresionan a cualquier ser humano. Es posible que del mismo modo que los escaladores y espeleólogos de hoy, que sienten una necesidad intensa y constante de necesaria exposición al vacío, los antiguos pobladores andinos sintieran la misma necesidad de retar la verticalidad. Las obras arqueológicas parecen atestiguar el autocontrol y la seguridad de sus antiguos constructores.

\section{LAS RUTAS VERTICALES Y EL POBLAMIENTO DE LOS ANDES PERUANOS}

El movimiento de los primeros pobladores entre las zonas altas y bajas de la cordillera peruana, forman parte de las hipótesis explicativas del poblamiento andino. En el Perú se han encontrado sitios tempranos entre los doce y ocho mil años AP que se ubicaban unos en la puna y otros en la Costa. En las quebradas intermedias y localizados a diferentes alturas, también se han registrado ocupaciones tempranas en abrigos y cuevas y todos ellos indican que se explotaban los distintos pisos ecológicos de las cuencas.

Basten algunos ejemplos de este proceso. Hay una cantera de obsidiana en el sitio llamado Alca, en el valle de Cotahuasi, Arequipa, a una altura aproximada de $4000 \mathrm{~m}$ (Jennings y Glascock 2002); restos de esta obsidiana fueron 


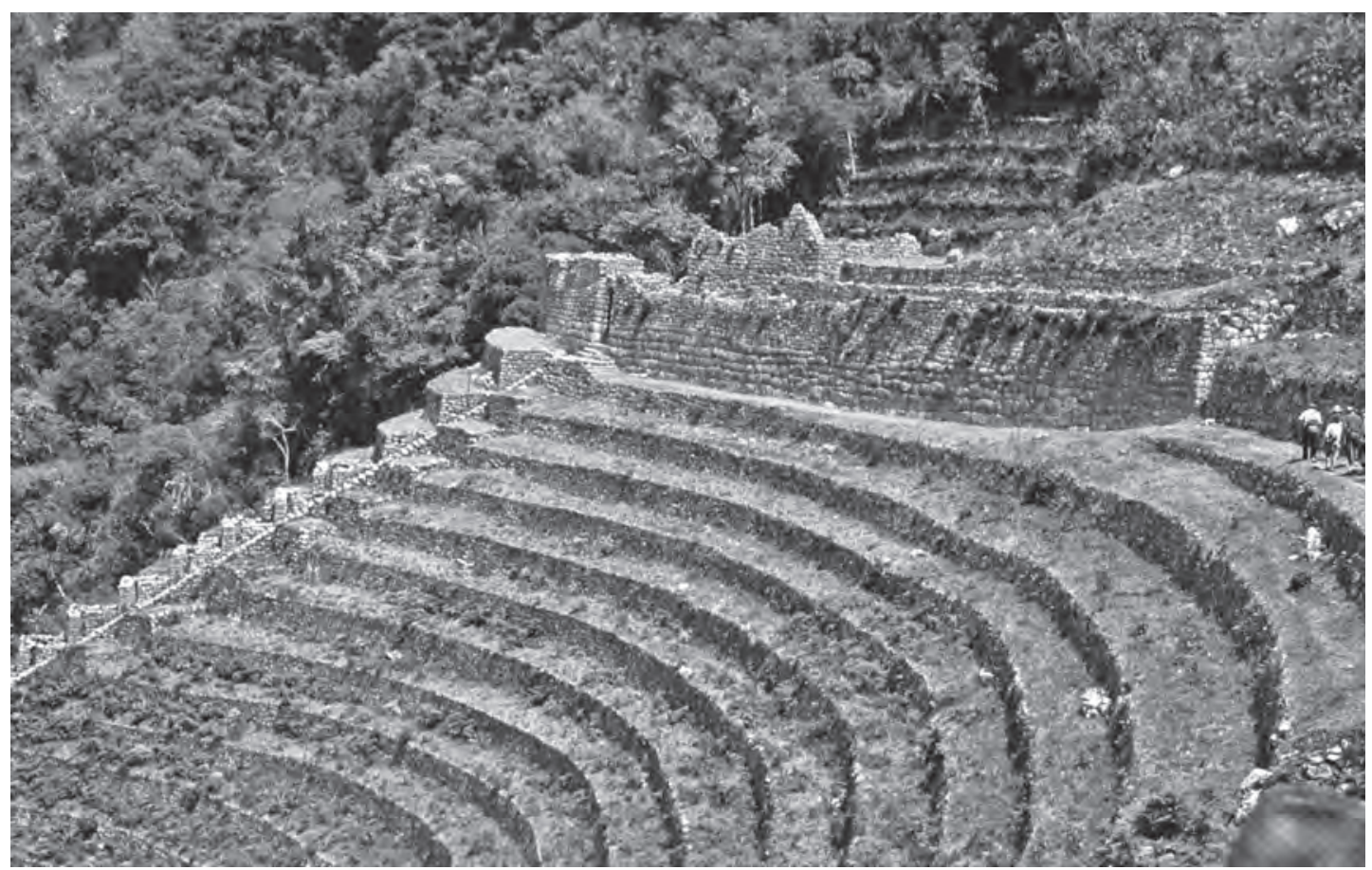

Andenes de Wiñaywayna, en Machu Picchu. Fotografía de Elías Mujica.

encontrados en la Costa, en el sitio de Jaguay, cerca a Camaná, a $130 \mathrm{~km}$ de distancia bajando por las quebradas andinas y asociada a poblaciones de pescadores y marisqueadores. Las dataciones de $\mathrm{C}^{14}$ dan once mil años para las capas asociadas con esta obsidiana (Sandweiss et al, 1998). A nivel de los valles interandino, en la Sierra Central del Perú, por ejemplo para la cuenca del rio Shaka - Palkamayo, Lavallee (1997) registró abrigos y cuevas con una antigüedad entre el 9000 y 5000 AP ubicados a distintas alturas y asociados a la explotación de distintas zonas de recursos. Igualmente en la Costa Norte, las pampas de Paiján, se demostró que estos grupos humanos pudieron haber ido ascendiendo por las quebradas por lo menos hasta los $2000 \mathrm{~m}$ de altura (Gálvez Mora 2002). En la Sierra Sur, el sitio de Toquepala (Muelle y Ravines 1963,1964$)$ a $2700 \mathrm{~m}$ de altura, con las pinturas rupestres más bellas del Perú y con una antigüedad de 9000 años AP, se constituye como un sitio intermedio entre los movimientos de grupos de pescadores de la Costa y los cazadores de guanacos de la sierra. Los arqueó- logos del norte chileno encontraron evidencias como huesos de pescado y mariscos en los sitios de Patapatane y Las Cuevas; 7550 - 6000 AC; Arriaza 1995:41, 2003: 79) ubicados en la puna sobre los $4000 \mathrm{~m}$ de altitud.

El uso vertical de las zonas ecológicas y productivas fue una constante a lo largo de todo el proceso andino desde los orígenes del poblamiento de los Andes peruanos. En los periodos posteriores a estas ocupaciones del Holoceno temprano, se siguen muchas otras estudiadas por los arqueólogos y que dan fe del traslado vertical de hombres y objetos. Durante los periodos Arcaico final y el Formativo se encontraron templos correspondientes a sociedades que fueron ocupando cada vez nuevas regiones y nuevas alturas. Luego, el control de zonas de recursos a distintas alturas de los valles llevaron a enfrentamientos entre los pueblos, situación que perduró hasta la aparición de la sociedades Wari y posteriormente la Inca. A lo largo de este proceso de "verticalización" de la sociedad, las rutas se irían convirtiendo en caminos que articularon a los distintos pisos ecológicos. 


\section{LOS CAMINOS}

Los Andes están llenos de senderos, huellas y caminos de herradura, muchos son sencillos y aun muy transitados, otros están abandonados. Estos caminos quedan manifiestos ya desde el Arcaico final y el Formativo hace ya por lo menos 5000 años. La sierra y la costa empezaron a desarrollarse, si bien cada una con su especificidad, también con una serie de rasgos comunes que sólo pudieron darse a partir del movimiento de personas, objetos e ideas marchando por rutas y caminos verticales y en pendiente. En estas rutas, se establecieron una serie de templos o paraderos rituales que venían a representar la forma de articulación vertical del territorio. Se desarrolló una arquitectura de templos que compartían todos una serie de características formales (los templos en $\mathrm{U}$, los pozos circulares hundidos, los patios hundidos al interior de los recintos ceremoniales) y una serie de objetos cerámicos, textiles, óseos, abalorios y adornos que también que provenían de regiones alejadas, al igual que los motivos iconográficos que las adornaban. Esta primera gran articulación vertical del territorio encuentró su punto culminante con la civilización Chavín.

Hacia el 600 d.C. los caminos estaban ya formalizados. Fueron usados por los wari para el establecimiento de su gran primer imperio panandino y serían la base de aquellos usados por los incas con sus mismos fines. Los grandes centros wari en la costa como el de Cajamarquilla en Lima y muchos otros repartidos a lo largo de casi toda la costa peruana, estaban comunicados con su capital en Ayacucho, sobre los 3200 m de altura, por caminos ya bien establecidos. Nueve siglos después, el Qhapaq Nan, camino real incaico, destinado también al tránsito de ejércitos y bienes, disminuía las dificultades de la verticalidad al transitar por las zonas más planas y altas de la puna. Estos caminos de puna eran a veces grandes empedrados atravesando planicies y humedales o a veces simples marcas en el terreno pero claramente delimitadas. Los caminos que bajaban hacia la costa o hacia la selva alta y la selva baja debían de vencer las grandes pendientes atravesando los valles encañonados, caminar por empinadas laderas debido muchas veces a la imposibilidad de hacerlo por las partes bajas de las cuenca, e implicaban, sobre todo, tener un eficaz sistema de organización para ser constantemente reparado ante las caídas de piedras, tierra, derrumbes o simple desgaste natural o del tiempo. Los caminos que discurrían cortando las laderas andinas requerían de mejor tecnología, dando forma a verdaderos homenajes a la verticalidad, tanto por las técnicas desplegadas, como por las rutas seguidas. Son remarcables, por ejemplo, el camino de Xauxa en la sierra central hasta Pachacamac en la costa limeña o el camino desde Vilcashuamán en Ayacucho y que conducía hasta el gran reino de Chincha o los caminos entre Cuzco y las costas de Arequipa por las cuencas de los río Cotahuasi - Ocoña y del Colca - Majes. Sin embargo, los caminos que constituyen el mayor desafío registrado hasta ahora, son aquellos que encontraron en Machu Picchu y en los alrededores del sitio (2006, 2007 y agosto 2009), el equipo Ukhupacha, espeleólogos españoles especialistas en las técnicas de progresión vertical, junto con los arqueólogos peruanos que allí trabajan. Angostos caminos pegados a farallones totalmente verticales, de más de medio centenar de metros de vacío que constituyen realmente un reto para el equilibrio y para la tecnología caminera.

Finalmente no debemos olvidar la importancia de los puentes para atravesar el vacío entre las márgenes de las quebradas. Se construyeron muchos puentes de piedra y de madera para atravesar ríos y humedales. Sin embargo, eran los puentes colgantes los más largos retando verdaderamente a la gravedad y cruzando grandes espacios de vacío ( 15 a más $50 \mathrm{~m}$ ) entre los márgenes de las quebradas. Hechos de ichu, nombre genérico de especies de pasto de fibras largas de las alturas andinas, debieron haber existido cientos de ellos en el territorio peruano según Hyslop (1992). Un ejemplo vivo de aquellos puentes es el de Queswachaca sobre el río Apurímac, recientemente declarado en el Perú Patrimonio Cultural de la Nación, con una longitud aproximada de $30 \mathrm{~m}$ y un ancho de 1.20 $\mathrm{m}$. Su elaboración e instalación reúne hasta un millar de personas de las comunidades cercanas. También se registró el uso de oroyas por los pueblos precoloniales (ibíd.). 


\section{LA GRAVEDAD ANDINA}

\section{La arquitectura}

La arquitectura es por definición un reto a la gravedad. El levantamiento de volúmenes arquitectónicos requiere el diseño de relaciones de equilibrio entre sus componentes, de modo tal que estos puedan mantenerse en pie sin caerse. Sin embargo, la arquitectura no diseña solamente volúmenes sino plantea, con la misma fineza, especialmente las superficies horizontales que hacen que estos volúmenes sean habitables para fines domésticos, laborales, rituales, productivos, económicos o para cualquier otra actividad humana.

Los Andes presentan planicies en las cuales se hicieron variadas e importantes edificaciones precoloniales. Pero vivir en el paisaje vertical, especialmente en las zonas adonde el cuerpo se asoma al vacío, hacía necesaria la creación de espacios horizontales. La arquitectura era una forma de amarrarse al piso y poder siempre escalar en lo vertical: plataformas, terrazas, excavaciones en las rocas, rellenos de tierra y cantos, terrazas que permitieran escalonar las inclinadas cuestas. Pero había que saber dónde construir las edificaciones domésticas y productivas; por ejemplo, las masas rocosas que servían de apoyo no debían mostrar desplazamientos o derivas, debían ser suelos bien consolidados sin peligro de deslizamientos en las partes inferiores que pudieran arrastrar consigo a toda la construcción. Había que manejar todos los elementos y recursos necesarios para poder $a b$ sorber y soportar las cargas verticales (amortiguamiento, consolidación - compactación del suelo, suspensión, soportes, contrapesos, otros). Machu Picchu es casi un caso emblemático de estas tecnologías de construcción en cimas y laderas, allí es evidente cómo la construcción de andenes y terrazas de cultivo bajo los recintos y plazas tenían la principal función de evitar los deslizamientos de los suelos de soporte del complejo.

La maestría de la arquitectura precolonial ligada a los espacios verticales alcanzó niveles importantes entre el 900 - 1400 d.C. y luego con el Tawantisuyu (1420 - 1532 d.C.) En las cimas y faldas inclinadas de las montañas se levantaron aldeas, fortificaciones, templos e infraestructura ligada a las actividades productivas. Se usaron los sólidos afloramientos rocosos para ganar alturas considerables que dificultaron los ataques de cualquier enemigo; se aprovechó al máximo el suelo agrícola en bancales y andenes bajando por ellos desde las aldeas en las cumbres; se facilitaron los accesos desde los caminos que venían por las partes altas de la suni y las punas o subían por las quebradas; se podía, además, divisar las tierras comunales o marca a grandes distancias y se podía, al mismo tiempo, ser visto desde ellas; pero además, se daba la impresión de poder y de grandeza. Estas construcciones, que nos asombran aun hoy, podemos encontrarlas a lo largo de toda la sierra peruana, pero pueden mencionarse especialmente las construcciones de Amazonas en el valle del Utcubamba, las del valle del Marañón y Tantamayo, las del Mantaro y el Pampas en Ayacucho y Huancavelica, las de las cabeceras de los ríos Chillón y Rimac, las de los quechuas preincaicos en el Cusco y muchas otras.

\section{La agricultura}

Si bien en las planicies altoandinas y costeras hay extensiones considerablemente óptimas para la agricultura, éstas en comparación con el total del territorio en laderas son minoritarias. Los suelos con pendiente pronunciada ocupan 58 millones de hectáreas (45\% del territorio nacional) y los suelos con problemas de fertilidad se extienden a 77 millones de hectáreas (60\% del territorio nacional) (Carrasco, Saez y Mejía 1993:35). Como es de suponer, en las laderas andinas, por lo general muy inclinadas, la fuerza de gravedad es un factor determinante, y no sólo para la agricultura sino también para los asentamientos y para la infraestructura construida como veremos más adelante. Debido a ello, las lluvias, la sismicidad, los cambios de temperatura o la irradiación solar pueden ser factores desencadenantes de intensos procesos erosivos que ponen en riesgo inclusive la vida humana si es que no se desarrollan formas de vida adecuadas a este tipo de geografías (Amat y León 2003). 


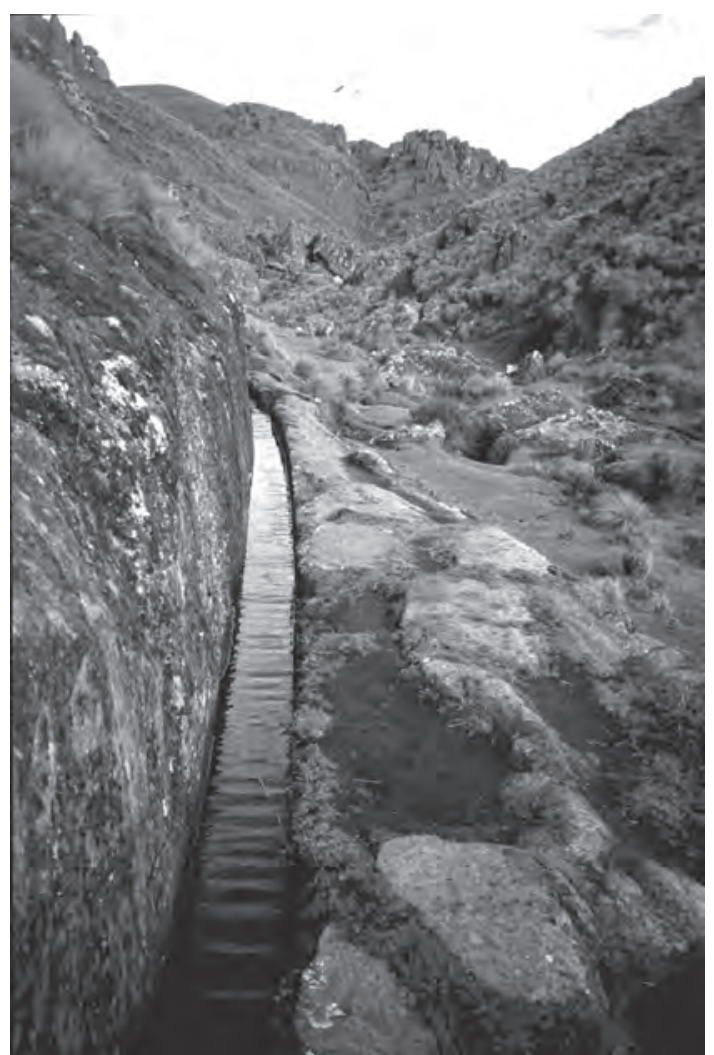

Cumbe Mayo. Fotografía de Elías Mujica.

Esta verticalidad condicionó también la agricultura precolonial en los Andes peruanos, su descubrimiento y su desarrollo hasta llegar a la creación de las terrazas y andenes. La agricultura fue producto de la observación de los ciclos reproductivos de las plantas y animales por los primeros habitantes andinos que seguían circuitos estacionales recorriendo los distintos pisos verticales de los Andes. De los valles y quebradas de la costa y la ceja de selva se empezó recogiendo las mejores semillas, trasladándolas de una altura a otra, de un sitio a otro y aprendiendo a reproducirlas. Entre el octavo y el tercer milenio AP la mayoría de las plantas cultivadas ya se habían "inventado" y se inició el proceso de transformación agraria del territorio; fue cuando cada sociedad comienza el dominio y transformación de su ambiente natural para la producción agrícola con cultivos para manufacturas como el algodón o para alimentarse, como el maíz. Ya con Chavín, en el 1500 a.C., se encuentran obras de canalización de los ríos y posibles áreas de inundación para uso agricola. En el 900 a.C. ya se hacían terrazas asociadas a cultivos en el sitio Pukara en Puno (Mujica 1995). En Marcavalle, Cusco, Mohr-Chávez $(1980,1981)$ ha sugerido cultivos asociados a las terrazas cercanas de 2800 años AP. Hace 2500 años se hicieron las primeras terrazas de cultivo por riego conocidas en Pachma, Ancash (Rosas La Noire, 1992). En Ayacucho, Lumbreras (1974) ha propuesto la presencia de terrazas de cultivo desde hace 1700 años por la cultura Huarpa. Hace 1400 años se inició un gran proceso de expansión de las terrazas con el Imperio Wari, el cual se intensificaría y perfeccionaría con los incas (Mujica 1995, citando a Keeley, y Meddems 1992) quienes en un siglo, hace 600 años, se encargarían de su implantación panandina en Ecuador, Chile y Bolivia.

Del total de laderas, Masson (1993: 6) registró un millón de hectáreas que fueron transformadas en zonas productivas mediante andenes y terrazas a lo largo de todo su proceso histórico. De estos, hasta hace 16 años, un 75\% aproximadamente se encontraban sin uso y en proceso de destrucción ${ }^{6}$. La construcción de andenes y terrazas no se hizo en forma improvisada. Aunque en general estos muestran que fueron ampliados progresivamente, siempre siguieron un plan general relativo al manejo integral de la ladera. Las terrazas agrícolas permitían uniformizar las condiciones productivas en las faldas inclinadas de las montañas y la articulación entre las zonas de producción agrícola para determinados cultivos y los pisos ecológicos. Favorecían el control y administración de la producción en escala local y regional potenciando la capacidad organizativa de las sociedades precoloniales. Eran también fundamentales para poder incrementar la cantidad de suelo agrícola y su calidad mediante el transporte de éstos para su construcción. Por su ubicación estratégica permitían un mejor control de la humedad, los vientos y las heladas y

\footnotetext{
6Entre 1981 y 2007 según las estadísticas del Programa Nacional de Manejo de Cuencas Hidrográficas y de Suelos - PRONAMACHS, ha reacondicionado 245,741 ha de las terrazas existentes. <http://www.pronamachcs. gob.pe/>
} 
facilitaban una mejor distribución del agua, en el caso de las terrazas de secano facilitaban el drenaje o el empozamiento del agua (Earls 1979, 1987,1989; Lumbreras 1974: 87-88; Ravines y Solar 1980:76-81; Alfaro y Cárdenas 1988: 33; Araujo 1986; Málaga 1987; Schjellerup 1987; Lumbreras 1990: 4). Pero un factor de suma importancia era prevenir y evitar la erosión y los huaycos o deslizamientos muy comunes en los Andes manejando, gestionando y previendo el riesgo físico. Organizar la producción agraria verticalmente en andenes y terrazas era, al mismo tiempo, minimizar permanente el riesgo agrario realizando cultivos en múltiples chacras o campos de cultivos, según la previsión climática, escogiendo los mejores para situaciones de mucha precipitación o para los años secos. Según esto se escogían las laderas a cultivarse, el tipo de surco a utilizarse, la preparación de los sistemas de drenaje y por último las variedades de los cultivos a sembrarse en cada temporada (Grillo 1988) tratando de usar la fuerza de gravedad a favor del manejo del agua y de los cultivos. Se trataba, finalmente, de garantizar al máximo posible para la época, la seguridad alimentaria de la sociedad.

Cuando se habla de la verticalidad andina no podemos olvidar las tesis de Murra (1975), las cuales se ocupan de la organización socioproductiva de la actividad agraria y su organización territorial en forma de un "archipiélago vertical" . La organización productiva agraria se hacía en función a la explotación simultánea de diversos pisos ecológicos y siguiendo un modelo de establecimiento de colonias las cuales conformarían los archipiélagos. Esa organización es una de las peculiaridades más saltantes del mundo andino precolonial, la que junto a la visión de las laderas escalonadas hablan de la sabiduría agraria precolonial, hoy en proceso de abandono y olvido. Son dignas de verse aquellas de gran factura en el Cusco o las de Torata en Moquegua, las de Tarata en Tacna, las de Andamarca en Ayacucho, las del Colca y el Cotahuasi en Arequipa, las de Antabamba, Aymaraes y An-

7 Murra también reconoce la verticalidad del paisaje. Dice: las montañas se deslizan casi verticalmente como base de sus postulados. dahuaylas en Apurímac o las de Cuyo Cuyo en Puno que marcan el límite con la ceja de selva.

\section{La gravedad y el Ucupacha}

La gravedad, definida de forma simple, es la fuerza de atracción entre dos cuerpos. En términos de una dialéctica sencilla, es básicamente la oposición entre el peso y la levedad, entre flotar y caer. En un territorio vertical como los Andes, manejar la gravedad es manejar los elementos, energías y fuerzas que no permitan caer a las cosas por su propio peso por los precipicios o laderas. Como es lógico suponer, cualquier sociedad debió desarrollar conocimientos acerca de la gravedad, pero no todas las realizaron en condiciones extremas como en los Andes peruanos.

En el universo andino no se da el concepto de caída, sin embargo, las cosas caen: "No hay nada en el Kay Pacha ${ }^{8}$ que suene a caída" (Mariano M. 1999:37). La pregunta es entonces, si en el mundo andino real, el de la tierra o Kay Pacha, esencialmente vertical, donde todo cae sino se evita, y si no lo evitas, pierdes tus construcciones o la vida: ¿Por qué en ese mundo el pensamiento cosmogónico no incluyó el hecho de "caer" entre sus conceptos? iSe encontraba enmascarado o es que el simple miedo que pudiera generar su existencia hacía evitar su mención?. Tal vez, "caer" era un presagio de destrucción excluido de toda posibilidad filosófica ante la intervención humana, pero no de toda probabilidad real. Estas tres dimensiones cosmogónicas andinas precoloniales, conjugaban la "ciencia andina precolonial", entendida ésta como el conocer, explicar e interpretar la naturaleza para su transformación positiva, pero en términos de convivencia con la naturaleza y renovación de la vida y como tal, siempre incluida en esa cosmogonía que, supuestamente, cubría todas las acciones andinas desde la pers-

8 Kay Pacha Mundo de arriba o lugar adonde habitaban los muertos y las ánimas; Hanan Pacha, la tierra o Pachamama; Ucu Pacha mundo de adentro o de debajo de las semillas que germinan y de los muertos El Ucu Pacha en su dimensión de mundo de abajo, es también concebido como mundo de adentro (Mariano M. op cit.) 
pectiva de la religión, el mito o la leyenda?.

Es posible decir que la organización socioeconómica basada en la dualidad de arriba (hanan) y abajo (urin), tan presente en el mundo andino, nombrada por muchos de los primeros cronistas, y que aún perdura en algunas poblaciones y en los nombres de pueblos y lugares, tuviera totalmente que ver con la organización vertical del territorio andino. Lo mismo sucede con el Hanan Pacha, el Kay Pacha y el Ucu Pacha que denotan tres lugares de la verticalidad y que es por donde discurría la vida humana. Esta comprensión del mundo y su organización desde la perspectiva vertical hoy día se ha perdido y la verticalidad se ha convertido en un factor no controlado, de desastres naturales y que es considerado en como una limitante para el desarrollo.

\section{El Patrimonio cultural y el paisaje vertical}

Hoy en día, el Perú es un territorio rico en patrimonio arqueológico que expresa cómo las sociedades precoloniales intervinieron y transformaron los factores verticales aprovechándolos a su favor, construyendo el paisaje vertical andino. Hoy día, de modo contrario, el territorio se encuentra sometido a los efectos negativos de una verticalidad débilmente controlada. Sitios arqueológicos y pueblos actuales viven en riesgo permanente al encontrarse ubicados en pendientes de alta inclinación sujetas a erosión se-

9 Cuando la conquista castellana del Tawantisuyu, el imperio de los incas vivía un proceso de civilización en el cual la observación del comportamiento de la naturaleza y su uso para las tareas productivas y de transformación de paisaje, no era ya una tarea focalizada en una sola región, en un solo pueblo o en una clase social. A este respecto es interesante notar que los procesos de experimentación agrícola, arquitectónica, ingenieril, astronómica, de producción de bienes y otros, se vuelven más intensos y al mismo tiempo más generalizados; es posible que la ciencia andina, aquella combinación entre conocimiento, simbolismo mítico, leyes sociales y comportamientos individuales, fuera constituyendo cada vez más un corpus que, fuera crítica permanente de la organización religiosa del imperio. No sabemos la historia de los "científicos" andinos de la época precolonial, pero lo cierto es que sin eso que los occidentales llamamos ciencia, no se hubiera construido ni el Tahuantinsuyo ni la civilización que le dio origen. vera, en zonas de sismicidad altas y medias con peligro de licuación de suelos y deslizamientos, en zonas de derrumbes de rocas y de aluvión, en zonas de inundaciones de lagunas y glaciares por los acelerados deshielos, en general, en zonas de peligro geológico. Todos estos factores de riesgo requieren se controlados; la experiencia precolonial obliga a pensar en la necesidad de la observación permanente de los factores de la verticalidad pero sobre todo, en la también permanente necesidad de intervenir a fin de evitar que la fuerza de la gravedad, que no descansa, haga que todo caiga y ruede por los cerros y montañas. Sin embargo, las presiones de otras prioridades dejan de lado la verticalidad y la conciben como un obstáculo para el desarrollo antes que como un recurso.

Evitar el colapso de gran parte del patrimonio cultural y recuperar el paisaje vertical implica ver el problema de forma integral. Actualmente el reglamento de investigaciones arqueológicas del Perú integra el concepto de paisaje cultural arqueológico, el cual debe servir de palanca para abordar conjuntamente la problemática de este rico patrimonio en conjunto con su paisaje asociado, especialmente en los casos de aquellos lugares en los cuales aparte de las construcciones se encuentran también los restos del territorio construido a partir de caminos y áreas de andenes y terrazas, represamientos, muros de contención que, en la mayoría de los casos, no son tomados en cuenta como parte de este patrimonio. Igualmente las regulaciones del ordenamiento territorial respecto a las Zonificación Económica y Ecológica regulan la necesidad del registro de los paisajes agroarqueológicos. Sirva este artículo para impulsar la importancia de la visión de la verticalidad andina desde sus diversas facetas como parte de la necesidad de vivir en un territorio equilibrado y ordenado.

\section{BIBLIOGRAFÍA}
Alfaro M., Julio; Alberto Cardenas
1988 Manejo de cuencas: hacia una nueva es- trategia del desarrollo rural en el Perú. Fundación Friedrich Ebert, Perú.


Amat y León, Carlos

2003 "Desarrollo territorial rural". En <http://www.iadb.org/sds/doc/ RUR Cap4 desarrolloterritorialrural. $\operatorname{pdf}>\overline{(14 / 09 / 09)}$.

Arregui, Alberto; Juan Cabrera, Fabiola León Velarde, et al.

1995 "Mal de Montaña, migraña y depresión: Coexistencia casual o causal? Posible rol de la hipoxia ambiental". Revista Medica Herediana, oct./dic 1995, 6(4):163-167. ISSN 1018-130X.

Araujo, Hilda

1986 "Hacia una política nacional de rehabilitación de andenes". En: Andenería y conservación de suelos y desarrollo rural en los andes peruanos. Javier Portocarrero Maish editor, Segunda edición, Perú.

Brack Egg, Antonio

1986 "Ecología de un país complejo". En Gran geografía del Perú: naturaleza y hombre. Volumen II. Manfer,-Mejía Baca. España.

Carrasco, Carmen; Luis Saez; Juan Mejía

1993 "Inventario y evaluación de los recursos agua, suelo y de infraestructura de riego". En Gestión del agua y crisis institucional. Cap. 1. Tecnología Intermedia (ITDG), Servicio Holandés de Cooperación Técnica, (SNV), Grupo Permanente de Estudio sobre Riego.

Chacón, Néstor; Javier Jacay; Iván Moreno

2005 "Procesos geodinámicos en el área del río Quillcay, Huaraz-Ancash". Revista del Instituto de Investigaciones de la Facultad de Minas, Metalurgia y Ciencias GeográficasUNMSM. Vol. 8 № 16, 2005: 22-28. $<$ http://www.scielo.org.pe/scielo. php?script $=$ sci_arttext\&pid $=$ S1561 $08882005000200003 \& \operatorname{lng}=\mathrm{es} \& \mathrm{nrm}$ $=$ iso\&tlng $=\mathrm{es}>(10.10 .2009)$.

Earls, John

1979 "Astronomía y Ecología: la sincroniza- ción alimenticia del maíz". En Allpanchis Phuturinqa Vol. XIII(14):117-135. Instituto de Pastoral Andina, Cuzco, Perú.

1986 "Evolución de la administración ecológica Inca". En Andenes y camellones en el Perú andino. COCYTEC, pp.23. 57, segunda edición, Lima, Perú.

1989 Planificacion agricola andina. Universidad del Pacífico. Ediciones COFIDE.

Gálvez Mora, César

2002 "Cazadores-recolectores $(10,000$ 5000 a.C.)". Atlas Ambiental de la Ciudad de Trujillo, pp. 48. Municipalidad Provincial de Trujillo, Trujillo.

Grillo, Eduardo

1988 Agua y agricultura andina. CAME Proyecto de tecnologías campesinas. CEPIS.

Jennings Justin; Michael D. Glascock

2002 "Description and Method of Exploitation of the Alca Obsidian Source, Peru". En Latin American Antiquity. March, Volume 13, Number 1.

Keeley, Heln C. M.; Frank M. Meddems

1992 "Prehispanic agricultural terrace systems in the Chicha-Soras Valley,Peru". Institute of Archaeology Bulletin. University College: University of London; 29: 121-138.

Lavalleé, Daniele

1997 "Territorio, recursos líticos y estrategias de aprovisionamiento en la cuenca del alto Rio Shaka (Junín, Perú)”. En Varón R. (ed.), Antropología, Arqueología e Historia de los Andes, Homenaje a María Rostworowski, Lima, Instituto de Estudios Peruanos, pp. 353-378.

León-Velarde, Fabiola

2007 "Clinical features and Physiopathology of Chronic Mountain Sickness". Disertación, Departamento de Ciencias Biológicas y Fisiológicas, Instituto de Investigaciones de la Altura (IIA). Universidad Peruana Cayetano Here- 
dia Sickness. < http://www.worldcongress2007.org.uk/images/Anthropology, physiology and illness in the Andes Clinical features and physiopathology of CMS - Fabiola Leon Velarde.pdf $>$

Lumbreras S., Luis

1990 Visión arqueológica del Perú milenario. Editorial Milla Batres S.A. Marzo1990, Lima.

1974 Las fundaciones de Huamanga. Publicación hecha por el Club Huamanga, primera edición, Lima.

Mariano M., Isabel

1999 "La filosofía peruana frente al problema de los orígenes". En Revista de Hispanismo Filosófico [Publicaciones periódicas]. № 4: 29 - 45. Asociación de Hispanismo Filosófico, España.

Málaga M., Alejandro

1987 "Los andenes en la agricultura collagua". En Andenes y camellones en el Perú andino. CONCYTEC, pp.127. 132, segunda edición, Lima, Perú.

Masson Meiss, Luis

1994 "Contribución al conocimiento de los Andenes". En Debate Agrario. Análisis y alternativas, № 19: 1 -27. Centro Peruano de Estudios Sociales.

Mohr-Chavez, K.

1969 "Excavations in the Cuzco-Puno Area of Southern Highland Peru". Expedition II(2):48-51.

1980a "The archaeology of Marcavalle, an early horizon site in the valley of Cuzco, Peru: Part I". Baessler-Archiv N.F. 28(2):203-329.

1981b "The archaeology of Marcavalle, an early horizon site in the valley of Cuzco, Peru. Part II". Baessler-Archiv N.F. 29(1):107-25.
Mujica B., Elías

1995 "Terrace culture and Pre-Hispanic traditions". CIP Circular. Lima: International Potato Centre ; 21 (2): 11-18.

Murra, John

1975 "El control vertical de un máximo de pisos ecológicos en la economía de las sociedades andina". En Formaciones económicas y políticas del mundo andino. Lima: IEP.

Pulgar Vidal, Javier

1967 Geografía del Perú: Las ocho regiones naturales. Editorial Ausonia. Lima.

Ravines, Roger; Félix Solar la Cruz

1980 "Hidráulica agrícola prehispánica". En Allpanchis Phuturinqa Vol. XIV (15):69-81. Instituto de Pastoral Andina, Cuzco, Perú.

Rosas La Noire, Hermilio

1992 "Restos arqueológicos en Pachma Bajo (Ancash)". En Meggers, Betty J., editor. Prehistoria Sudamericana: nuevas perspectivas.Washington: Taraxacum; 333-341.

Sandweiss, Daniel H.; Heather Mcinnis; Richard L. Burger; Asunción Cano; Bernardino Ojeda; Rolando Paredes; María del Carmen Sandweiss; Michel D. Glascock

1998 "Quebrada Jaguay: Early South American Maritime Adaptations". En Science 281:1830 - 1832.

Shjellerup, Inge

1987 "Andenes y camellones en la región de Chachapoyas". En Andenes y camellones en el Perú andino. CONCYTEC, pp.133-150, segunda edición, Lima, Perú. 